\title{
The Role of Co-Skewness in the Pricing of Real Estate
}

\author{
Crocker H. Liu \\ New York University \\ David J. Hartzell \\ University of North Carolina \\ Terry V. Grissom \\ Texas A\&M University
}

\begin{abstract}
The current study investigates whether systematic skewness offers an alternative perspective as to why the risk-adjusted returns on real estate should be similar to that for stocks. This is not a trivial issue since an affirmative finding implies that we might be incorrectly measuring real estate risk from both a pricing and a portfolio allocation perspective. A multivariate test of the Kraus-Litzenberger model is used to investigate this skewness proposition with the K-LCAPM tested against several alternative versions of the CAPM. The study finds that the KrausLitzenberger model offers additional insights into the measurement of real estate risk. Evidence is also found that both the zero beta and the consumption-oriented CAPM hold, which is consistent with the recent literature in real estate.
\end{abstract}

Key words: Skewness, CAPM, Commingled real estate funds, Smoothing

Recent literature suggests that real estate does not earn excess risk-adjusted returns defined using second moments when the zero beta form of the CAPM is used. For example, Geltner (1989) notes that if appraisal-based returns are adjusted for smoothing, then real estate returns should exhibit similar behavior to stock returns in equilibrium using a consumption-oriented CAPM (CCAPM) framework, although Geltner does not formally test this assertion. In a related study, Liu and associates (1990a and 1990b) find that no return differential exists between asset classes when the missing asset phenomenon is corrected for in the market proxy and an adjustment is made for appraisal smoothing using the zero beta version of the CAPMUI. Although no evidence of excess risk-adjusted returns to real estate is found to obtain using a zero beta version of the CAPM, there are several reasons why one might want to examine an alternative capital market theory regarding the risk-return tradeoff between real estate and other assets. The most important reason, according to Kraus and Litzenberger (1976), is that

The ... Black (zero beta) modification results in a weaker positive theory since neither the magnitude of the slope nor the magnitude of the intercept in their capital market model is predicted [p. 1085; emphasis added]. 
Their point is that the inconsistency of the traditional CAPM could arise because systematic skewness is not considered. If systematic skewness is important to investors and is priced, then this suggests that risk for real estate should recognize both beta and systematic skewness.

Skewness in the context of a return distribution means that a higher probability exists that returns are either higher or lower than the mode or most likely value. If more returns are observed above (below) the most likely value than below (above), then the return distribution is said to exhibit positive (negative) skewness. According to financial theory, investors should prefer assets having a larger probability of very large payoffs: for example, assets with positive skewness ceteris paribus with investors only paying for that portion of skewness which is nondiversifiable. Prior evidence exists in the literature that real estate returns are not normally distributed. ${ }^{1}$ For example, McCue (1984, p. 90) observes that his quarterly data are

... not from a normal distribution. The holding period return's skewness coefficient is far in excess of the value that is consistent with a normal distribution. In addition to being large, the skewness coefficient of the holding period return is positive... Even the annual data, which is less influenced by the appraisal patterns maintains skewness...coefficients that are not consistent with normally distributed data."

McCue further notes that this positive skewness remains even in a large real estate portfolio, which implies that skewness has not been diversified away. However, the skewness in real estate returns which McCue examines is total skewness with no adjustment made for smoothing. In equilibrium, only the nondiversifiable portion of this skewness known as systematic skewness matters.

The current study investigates whether the recognition of systematic skewness can offer an alternative perspective as to why the risk-adjusted returns on real etate should be similar to that for stocks after a correction is made for smoothing in appraisal-based returns and a more complete market proxy is used. The hypothesis advanced is that the risk-return relationship for real estate will appear to be incongruous relative to that for other assets if asset returns are only adjuted for systematic risk but not for systematic skewness. This is based on the premise in

${ }^{1}$ An analysis of the data in Ibbotson and Siegel $(1983,1984)$ using the World Market Wealth proxy re
Jensen's alpha decreases as positive excess skewness decreases where total skewness rather than
a market proxy is measured. A Prob $<$ W of 50 percent or greater evidences normality.
\begin{tabular}{lllllll} 
Type of Real Estate & Jensen $\alpha$ & $T(\alpha)$ & Excess Skewness $\left(\mu^{3}\right)$ & Shapiro-Wilk W & Prob $<W$ \\
\hline Farm & .080 & 5.26 & 1.29 & .906 & .01 \\
Homes & .030 & 7.18 & 1.04 & .906 & .01 \\
Commercial R.E. & .016 & 2.58 & 0.38 & .956 & .46 \\
\hline
\end{tabular}

However, the only way to determine if skewness is incorporated in the market pricing of assets is through the use of an equilibrium model which looks only at the nondiversifiable component of skewness. 
finance that investors demand more compensation to hold a portfolio having a higher variance ceteris paribus, but they are satisfied with a lower mean return on a portfolio having a higher positive (or less negative) systematic skewness, all other things equal. Therefore, it follows that if investors have a choice between a real estate portfolio and a portfolio of stocks and the former portfolio has a greater positive skewness relative to the latter portfolio, then investors

will demand lower excess return on the real estate portfolio on average compared to the stock portfolio after adjusting for the variance risks of the respective portfolios. The point is that positive (or less negative) systematic skewness is desirable to investors while variance is undesirable.

The study finds that the Kraus-Litzenberger model provides some additional insight into real estate pricing. The Kraus-Litzenberger version of the CAPM is consistent with the return data for the asset classes examined. Besides this, not only is the sign of the skewness parameter negative but also the average systematic co-skewness value for real estate is less negative than that for stocks in general. This evidence supports the proposition that commercial real estate outperforms common stocks because the mean excess returns are adjusted only for systematic covariance (beta) but not for systematic skewness. This further suggests that the measurement of real estate risk should incorporate both systematic skewness and beta, and raises the possibility that systematic skewness might also influence the portfolio allocation decision. However, the return data also support both the zero beta CAPM and the zero beta form of the consumption-oriented CAPM. This is not unexpected since the three-moment CAPM represents an alternative explanation to the zero beta construct with its riskless surrogate portfolio which is uncorrelated to the market proxy. The study finds that these results are invariant to the market proxy chosen in general which is consistent with the findings of Stambaugh (1982).

The remainder of the article proceeds as follows. Section 2 develops a multivariate test for the Kraus-Litzenberger model; section 3 describes the data sources used in this study. Three market proxies are also employed to ascertain if systematic skewness is sensitive to the market proxy chosen given the criticisms of Roll (1977) and the findings of Stambaugh (1982). Section 4 reports the test results of the K-L CAPM and compares these results to several alternative twomoment versions of the CAPM; section 5 concludes the study.

\section{Developing a hypothesis and a multivariate test of the K-L CAPM}

This article tests the proposition that the risk-return tradeoff for commercial real estate is similar to that for common stocks if excess returns are adjuted not only for systematic covariance but also for systematic co-skewness. The rationale is that the recognition of systematic co-skewness (if significant) would result in a downward adjustment in real estate returns relative to returns on stocks if real estate returns have a higher positive (or less 
negative) systematic co-skewness with the market relative to returns on stocks. To test this hypothesis, the current study uses the following quadratic index model:

$$
\tilde{R}_{i}-R_{F}=c_{0 i}+c_{1 i}\left(\tilde{R}_{M}-R_{F}\right)+c_{2 i}\left(\tilde{R}_{M}-\bar{R}_{M}\right)^{2}+\tilde{e}_{i}
$$

Barone-Adesi (1985) has used this quadratic specification to reduce the severity of errors-invariables and multicollinearity associated with past tests of the K-L CAPM. ${ }^{2}$

The quadratic market model in equation (1) is a model for the return-generating process but it is not an equilibrium model. To relate this model to an equilibrium model, the following specification which is consistent with the $\mathrm{K}-\mathrm{L}$ three-moment CAPM is used to derive a constraint on the intercept of the quadratic index model: ${ }^{3}$

$$
\bar{R}_{i}-R_{F}=b_{1} \beta_{i}+b_{3} m_{i M M}
$$

where $\boldsymbol{R}_{\boldsymbol{F}}$ and $\overline{\boldsymbol{R}}_{\boldsymbol{i}}$ is unity plus the rate of return on the riskless asset and the expected rate of return on the ith risky asset, respectively; $\beta_{i}=\sigma_{i M} / \sigma_{M}^{2}$ is the beta of the ith risky asset, $\boldsymbol{m}_{\boldsymbol{i} \boldsymbol{M} \boldsymbol{M}}=\boldsymbol{E}\left[\left(\overline{\boldsymbol{R}}_{\boldsymbol{i}}-\overline{\boldsymbol{R}}_{\boldsymbol{i}}\right)\left(\overline{\boldsymbol{R}}_{\boldsymbol{M}}-\overline{\boldsymbol{R}}_{\boldsymbol{M}}\right)^{2}\right]$ is the systematic skewness of the $\boldsymbol{i}$ th risky asset, $\boldsymbol{b}_{\boldsymbol{i}}$ is the market price of systematic risk, and $\boldsymbol{b}_{\mathbf{3}}$ is the market price of systematic skewness. Alternatively, $\boldsymbol{b}_{\boldsymbol{i}}$ is the marginal rate of substitution (MRS) of the expected return for risk, while $\boldsymbol{b}_{\mathbf{3}}$ is the MRS between expected return and skewness. The constraint that the K-L model in equation (2) imposes on the intercept of the quadratic index model in equation (1) is

$$
c_{0 j}=c_{2 i} \sigma_{M}^{2}\left(2 b_{3} \sigma_{M}^{2}-1\right) \quad i=1, \ldots, N
$$

The complete derivation of this nonlinear restriction which the Kraus-Litzenberger threemoment CAPM places on a system of $\mathrm{N}$ regression equations is given in Appendix $\mathrm{C}$. Substitution of this nonlinear restriction into equation (1) yields the restricted version of the quadratic market model

$$
\begin{aligned}
& \tilde{R}_{i}-R_{F}=c_{2 i} \sigma_{M}^{2}\left(2 b_{3} \sigma_{M}^{2}-1\right)+c_{1 i}\left(\tilde{R}_{M}-R_{F}\right)+c_{2 i}\left(\tilde{R}_{M}-\bar{R}_{M}\right)^{2}+\tilde{e}_{i} \\
& i=1, \ldots, N
\end{aligned}
$$

\footnotetext{
${ }^{2}$ Kraus and Litzenberger (1976) report a correlation of .91 between the estimates of beta and systematic skewness. Friend and Westerfield (1980) also find that the regression coefficients reflect collinearity between the beta and co-skewness measures. Barone-Adesi (1985) suggests that this multicollinearity might account for the fluctuations evident in the Friend-Westerfield estimated risk premiums.

${ }^{3}$ This version of the Kraus-Litzenberger CAPM assumes that the return on the market proxy is normally distributed in contrast to the model which Kraus and Litzenberger (1977), Friend and Westerfield (1980), Sears and Wei (1988), and Lim (1989) actually test which assumes that the return on the market portfolio is asymmetrically distributed. In contrast to these studies, Barone-Adesi (1985) relates the APT model of Ross (1975) and Roll and Ross (1980) to the Kraus-Litzenberger quadratic market model.
} 
where $E\left(\tilde{e}_{i}\right)=0, E\left[\tilde{e}_{i}\left(\tilde{R}_{M}-R_{F}\right)\right]=0$, and $E\left[\tilde{e}_{i}\left(\tilde{R}_{M}-\tilde{R}_{M}\right)^{2}\right]=0 .^{4}$

The formal hypothesis tested, therefore, whether the K-L CAPM is consistent with the data, is

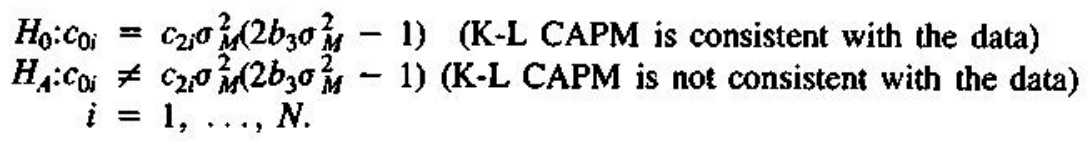

Support for the null hypothesis suggests that the K-L model is consistent with the data. We also test whether the systematic skewness parameter $\boldsymbol{b}_{\mathbf{3}}$ is negative $\left(\boldsymbol{b}_{\mathbf{3}}<\mathbf{0}\right)$ and significant since this hypothesis does not test whether systematic skewness is priced. K-L show that when equation (2) is the correct model, $\boldsymbol{b}_{\mathbf{3}}<\mathbf{0}$ under the assumption of decreasing absolute risk aversion. Furthermore, the avrage systematic co-skewness values, $\boldsymbol{m}_{\boldsymbol{i} \boldsymbol{M} \boldsymbol{M}}$, for real estate returns must be higher (more positive or less negative) relative to stock returns for our proposition to be supported.

The specification given in equation (2) assumes that the return on the market is normally distributed $\left(\boldsymbol{m}_{\boldsymbol{M}}^{3}=\mathbf{0}\right)$ which in turn implies that the multicollinearity between risk $\left(\boldsymbol{\beta}_{\boldsymbol{i}}\right)$ and skewness $\left(\boldsymbol{m}_{\boldsymbol{i} \boldsymbol{M} \boldsymbol{M}}\right)$ ) is reduced. ${ }^{5}$ Another advantage is that the issue raised by Sears and Wei (1985) concerning incorrect conclusions on the sign of the skewness parameter when the market risk premium is negative is obviated. ${ }^{6}$

${ }^{4}$ In the actual test of equation (2), the variance of the return on the market proxy in the nonlinear restriction is estimated in advance and is set to a control variable in the estimation process. In addition to this, since sample statistics rather than population parameters are used in the estimation process and the sample kurtosis is

$$
\left[\frac{T(T+1)}{(T-1)^{3}}\right]\left[\frac{\Sigma\left(x_{i}-\bar{x}\right)^{4}}{s^{4}}\right]=3 \quad \text { or } \Sigma\left(x_{i}-\bar{x}\right)^{4}=3\left[\frac{(T-1)^{3}}{T(T+1)}\right] s^{4},
$$

the actual nonlinear restriction tested given $T=44$ is $c_{0 i}=c_{2 i} s_{M}^{2}\left(238 b_{3} s_{M}^{2}-1\right)$ where $s_{M}^{2}$, is the sample estimate of $\boldsymbol{\sigma}_{M}^{2}$ and the number 238 is derived from

$$
\begin{gathered}
T=44 \Rightarrow\left[\frac{(T-1)^{3}}{T(T+1)}\right]=40 \\
\text { so } 3[40] s^{\wedge}-s^{4}=119 s^{4} \text {. Therefore, } c_{o i}=c_{2 i} s_{M}^{2}\left(2 * 119^{*} b_{3} s_{M}^{2}-1\right)=c_{2} s_{M}^{2}\left(238 b_{3} s_{M}^{2}-1\right) .
\end{gathered}
$$

${ }^{5}$ This follows from the proof in Appendix $\mathrm{C}$ which shows that $\boldsymbol{\beta}_{\boldsymbol{i}}=\boldsymbol{c}_{\mathbf{1 i}}$ and $\boldsymbol{m}_{\boldsymbol{i} \boldsymbol{M} \boldsymbol{M}}=\mathbf{2} \boldsymbol{c}_{\mathbf{2 i}} \boldsymbol{\sigma}_{\boldsymbol{M}}^{\mathbf{4}}$ given the assumption that the market return is normally distributed. On the other hand, multicollinearity is a problem when a nonsymmetrical distribution characterizes market returns, since in this case, a scalar differentiates $\boldsymbol{\beta}_{\boldsymbol{i}}$ and $\boldsymbol{\gamma}_{\boldsymbol{i}}$, that is, $\beta_{i}=c_{1 i}+c_{2 i}\left(\frac{m_{M}^{3}}{\sigma_{M}^{2}}\right)$ and $\gamma_{i}=c_{1 i}+c_{2 i}\left[\left(k_{M}^{4}-\sigma_{M}^{4}\right) / m_{M}^{3}\right]$.

${ }^{6}$ Sears and Wei point out that the market risk premium $\left[\boldsymbol{R}_{\boldsymbol{M}}-\boldsymbol{R}_{\boldsymbol{F}}\right.$ ] and an elasticity coefficient $\boldsymbol{K}_{\mathbf{3}}$ are embedded in both the risk premium for risk $\left(\boldsymbol{b}_{1}\right)$ and the risk premium for skewness $\left(\boldsymbol{b}_{2}\right)$ when the rate of return on the market portfolio is asymmetrically distributed

$$
E\left(\tilde{R}_{i}\right)-R_{F}=b_{1} \beta_{i}+b_{2} \gamma_{i}-E\left(\tilde{R}_{j}\right)-R_{F}=\left[\frac{\left(\bar{R}_{M}-R_{F}\right)}{\left(1+K_{3}\right)}\right] \beta_{i}+\left[\frac{K_{3}\left(\tilde{R}_{M}-R_{F}\right)}{\left(1+K_{3}\right)}\right] \gamma_{i}
$$


The three-moment K-L CAPM is tested against several alternative two-moment versions of the CAPM to see whether the three-moment CAPM provides an additional insight into the measurement of real estate risk to make the loss of parsimony worthwhile. The alternative two-moment versions of the CAPM tested include the traditional CAPM, the zero beta CAPM, and the consumption-oriented CAPM when the riskless asset is not observed. The test of the respective hypothesis is similar in nature to the K-L CAPM and follows Gibbons (1982). To test the traditional CAPM, the following market model is assumed to hold:

$$
\tilde{R}_{i t}-r_{f t}=\alpha_{i}+\beta_{i}\left(\tilde{R}_{M t}-r_{f}\right)+\tilde{\varepsilon}_{i t}
$$

where $\bar{R}_{M t}$ is the return on the market proxy and $r_{f}$ is the risk-free rate. The constraint that the Sharpe-Litner-Mossin CAPM imposes on the intercept of this market model is

$$
\alpha_{i}=0
$$

Alternatively, the test of both the zero beta CAPM and the consumption-oriented CAPM involve using the market model with returns used in lieu of excess returns:

$$
\tilde{R}_{i t}=\alpha_{i}+\beta_{i} \tilde{R}_{M t}+\bar{\varepsilon}_{i t}
$$

For either of these CAPM versions to hold, the following parameter restriction on equation (8) is necessary:

$$
\alpha_{i t}=\gamma\left(1-\beta_{i}\right)
$$

where $\boldsymbol{\gamma}$ is the expected return on the portfolio which is uncorrected with the market proxy $\boldsymbol{M}$. Alternatively, $\boldsymbol{\gamma}$ is the return on the risky surrogate for the riskless asset $\mathrm{r}_{\mathrm{f}}$ where $\boldsymbol{\gamma} \boldsymbol{> 0}$ and $\boldsymbol{\gamma}>$ $r_{\mathrm{f}}$ because $\boldsymbol{\gamma}$ is risky. The test of the consumption-oriented CAPM is identical to the test of the zero beta CAPM except that the former test uses a fixed weight proxy (MCP) that has the maximum correlation with growth in aggregate consumption, while the latter test uses three value-weighted indexes as alternative market proxies. Unfortunately, the hypotheses associated with the various CAPMs are non-nested, and therefore it is difficult to actually

Thus, incorrect conclusions on the sign of the risk premium for skewness $\boldsymbol{b}_{\mathbf{2}}=\boldsymbol{K}_{\mathbf{3}}\left[\boldsymbol{R}_{\boldsymbol{M}}-\boldsymbol{R}_{\boldsymbol{F}}\right] /\left(\boldsymbol{l}+\boldsymbol{K}_{\mathbf{3}}\right)$ arise when the market risk premium is negative $\left[\boldsymbol{R}_{\boldsymbol{M}}-\boldsymbol{R}_{\boldsymbol{F}}\right]<\mathbf{0}$. For the special case of a symmetrically distributed rate of return on the market portfolio, however, it is easy to verify that

$$
E\left(\bar{R}_{i}\right)-R_{F}=\left[\bar{R}_{M}-R_{F}\right] \beta_{i}+\frac{d \bar{W}}{d m_{W}} m_{i M M}
$$

where $\left(\boldsymbol{d} \overline{\boldsymbol{W}} \boldsymbol{l} \boldsymbol{d} \boldsymbol{m}_{\boldsymbol{w}}\right)=\boldsymbol{b}_{\mathbf{3}}$ is the change in average wealth given a change in the skewness of wealth. Consequently, the focus on whether $\boldsymbol{b}_{3}$ is less than zero does not lead to incorrect conclusions regarding the sign of skewness when the estimated market premium is negative, that is, $\left[\boldsymbol{R}_{\boldsymbol{M}}-\boldsymbol{R}_{\boldsymbol{F}}\right]<\mathbf{0}$. 
determine which version of the CAPM holds. In addition to the non-nested nature of the hypotheses, we know that the K-L CAPM degenerates to a two-moment CAPM if systematic skewness is not priced so it follows that the K-L CAPM should hold if a two-moment CAPM holds.

The empirical analysis in the current study therefore focuses on the sign implied by capital market theory and on the t-statistics of the constraint associated with the intercept term in the restricted version of the appropriate single (multi) index model. In summary,

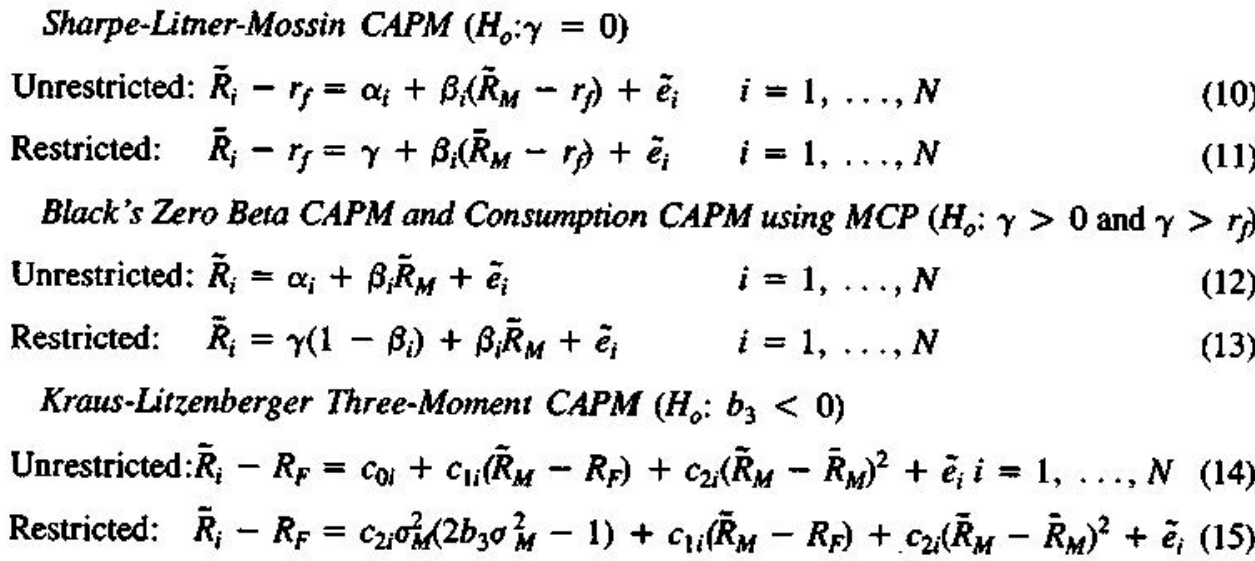

\section{Empirical tests: the multivariate approach}

\subsection{Data}

3.1.1. Asset return series. Quarterly holding period returns are computed for stock industry groups and commingled real estate funds (CREFs) for the period from March 1979 through December 1989. ${ }^{7}$ Quarterly price and dividend information on 49 industry groups are compiled from issues of Standard and Poor's Analyst Handbook, Monthly Supplement. ${ }^{8}$ Returns net of management fees for five open-ended equity CREFs are obtained either from the respective CREF or from an investment advisory firm. Three of the CREFs are sponsored by insurance companies while two CREFs are affiliated with banks. In addition to individual CREF returns, the CREF return series for all equity funds from Evaluation Associates is also obtained. Appendix $A$ lists the specific securities associated with each asset category.

\footnotetext{
${ }^{7}$ The availability of quarterly time-series returns for CREFs dictates the time interval evaluated, although this time period does encompass both a period of high inflation and a period of low inflation. High inflation characterizes the period from 1979 to the end of 1981 in general, while low inflation is associated with the post-1981 period. A potential source of positive return bias prevalent in most real estate studies is thus absent in the present study. ${ }^{8}$ All industries with continuous price and dividend data on a quarterly basis over the study period are used. The industry indices are value weighted and derived in an identical fashion to the S\&P500.
} 
3.1.2. The market indexes. Three value-weighted market proxies and one fixed-weight index are investigated given the criticisms of Roll (1977) that the particular index chosen as the market proxy might lead to different inferences about the traditional CAPM and the K-L CAPM. The first market index is the CRSP value-weighted stock return series which consists of all common stocks traded on the New York Stock Exchange (NYSE), American Stock Exchange (AMEX), and National Association of Security Dealers Automated Quotations (NASDAQ). Market proxy no. 2, known as the security market index (SMI), combines the CRSP value-weighted stock return series with returns on corporate bonds, government bonds, mortgage-backed bonds, and cash equivalents. The third value-weighted index, hereafter referred to as the U.S. market index (USMI), adds commercial real estate, farm real estate, and single-family homes to the SMI proxy. Both the returns on commercial real estate and farm real estate are adjusted for smoothing using the technique discussed in Firstenberg, Ross, and Zisler (1988). A more detailed discussion of this smoothing adjustment procedure is given in Appendix D.

In addition to the three value-weighted indexes, a fixed-weight market proxy known as the Maximum Correlation Portfolio (MCP) is constructed using the same six asset classes used to create the USMI proxy. The MCP index is used to test whether the consumption-oriented CAPM (CCAPM) holds when the riskless asset is not observed. Breeden, Gibbons, and Litzenberger (1989) define the MCP as the portfolio that has the maximum correlation with growth in aggregate consumption and show that the beta on an asset measured relative to the MCP is equivalent to the consumption beta for that asset divided by the consumption beta of the MCP. The weights for the MCP are calculated by running a regression of real consumption growth per capital on real returns from six asset classes with consumption growth scaled by .9375 as in Breeden, Gibbons, and Litzenberger (1989) to adjust for summation bias. The data are mean adjusted prior to running the regression. To calculate real consumption growth per capita, quarterly expenditures on nondurable goods (GCN) and services (GCS), the CPI-U index (PUNEW), and the total noninstitutional civilian population (P16) are obtained from the CITIBASE tape. To ascertain how strong the tendency is for the real returns on the MCP to move with real consumption growth per capita, the following regression is run:

$$
R_{M C P, t}=\underset{(-.269)}{-.0004}+\underset{(6.56)}{1.65 c_{t}^{*}}+\hat{u}_{M C P, t} \quad \mathrm{R}^{2}=.49
$$

where the t-statistics are given in parentheses, $\boldsymbol{c}_{\boldsymbol{t}}^{*}=. \mathbf{9 3 7 5}\left(\boldsymbol{c}_{\boldsymbol{i t}}-\boldsymbol{c}\right)$, and $\bar{c}$ is the sample mean of $\boldsymbol{c}_{\boldsymbol{i} \boldsymbol{t}}$. The coefficient of determination reveals that the MCP tracks consumption growth fairly well since the correlation between these two series is .70.

Table 1 reports the average weights used for each asset class in construing the USMI and MCP market proxies. The market values and underlying data sources used to construct the portfolio weights are discussed in Appendix B. Table 1 reveals that the MCP, in contrast to the USMI, 
places less weight on stocks, farm real estate, and single-family homes, and gives relatively more emphasis to cash and commercial real estate, as expected.

The sum of the asset submarkets does not represent the "true" U.S. market portfolio since assets such as human capital and consumer durables are omitted. A possibility also exists that some assets are overstated. ${ }^{9}$ Despite these shortcomings, the asset classes included do comprise the most liquid and identifiable components of investable capital wealth.

Table 1 . Market weights for U.S. market proxy (weights reported are for the fourth quarter of each year 1979Q1-1989Q4).

\begin{tabular}{ccccccc}
\hline Year & Stocks & Bonds & Cash & Commercial R.E. & Farms & Homes \\
\hline 1979 & .211 & .113 & .068 & .178 & .133 & .298 \\
1980 & .246 & .103 & .069 & .179 & .126 & .278 \\
1981 & .211 & .107 & .077 & .198 & .118 & .289 \\
1982 & .220 & .145 & .086 & .191 & .108 & .250 \\
1983 & .245 & .149 & .082 & .182 & .092 & .250 \\
1984 & .226 & .170 & .091 & .186 & .079 & .248 \\
1985 & .248 & .198 & .092 & .174 & .062 & .227 \\
1986 & .269 & .222 & .088 & .158 & .053 & .211 \\
1987 & .243 & .235 & .087 & .161 & .049 & .226 \\
1988 & .263 & .233 & .093 & .151 & .047 & .212 \\
1989 & .284 & .238 & .091 & .141 & .045 & .200 \\
Minimum weight & .192 & .095 & .063 & .141 & .044 & .200 \\
Maximum weight & .317 & .238 & .093 & .206 & .133 & .334 \\
Average weight & .240 & .165 & .081 & .172 & .085 & .257 \\
Standard deviation & .030 & .049 & .009 & .017 & .034 & .036 \\
\hline
\end{tabular}

Nore: The minimum, maximum, average, and standard deviation of the market weights for the USMI are computed using the full 44 quarters of market values for the respective asset classes.

Estimated fuxed weights for the maximum correlation portfolio (The MCP porffolio is used to test the conswnption: oriensed (APM).

The weights for the MCP portfolio are calculated by nunning a regression of real consumption growth on real returns from six asset classes with consumption growth scaled by .9375 as in Breeden, Gibbons, and Litzenberger (1989) to adjust for summation bias. The data are mean-adjusted prior to running the regression. The adjusted $\mathbf{R}^{2}$ for the regression is .43 and the $F$ statistic for testing the joint significance of all coefficients is 6.46 with a p-value of .0001 . The coefficients are rescaled so that they add to 100 percent.

\begin{tabular}{lcccccc}
\hline Category & Stocks & Bonds & Cash & Commercial R.E. & Farms & Homes \\
\hline Weight & .069 & -.085 & .544 & .304 & .034 & .134 \\
T-statistic & 2.49 & -1.46 & 1.43 & 3.15 & 1.26 & .83 \\
Prob $>|\mathrm{T}|$ & .02 & .15 & .16 & .00 & .22 & .41 \\
\hline
\end{tabular}

\subsubsection{Statistical properties of the market proxies. Table 2 reports the statistical properties} associated with the quarterly returns for the three market proxies utilized. The returns

\footnotetext{
${ }^{9}$ Double counting might arise since multiple financial claims on the same underlying asset are present. Examples of this include real estate and real estate mortgages and corporations that hold common stick of another corporation. The current study attempts to avoid the first type of double counting through using only the total equity value for various property types. Some types of double counting still remain, however, with the impact of omitted assets unknown.
} 
associated with each proxy are normal although some negative excess skewness exists. ${ }^{10}$ Normality of the return distribution for each market proxy is necessary in the current study since the version of the K-L CAPM tested assumes that a normal distribution is associated with the return on the market. Table 2 also reveals that the first four sample autocorrelations of the returns on the various market indexes are generally close to zero at all lags, with a high degree of correlation present among the returns on each proxy except for the correlation between the MCP and the other market proxies. This is not surprising since the MCP gives less weight to stocks and bonds in contrast to the other market proxies.

Table 2. Statistics on market proxies.

\begin{tabular}{|c|c|c|c|c|c|c|c|c|c|c|c|c|}
\hline \multicolumn{13}{|c|}{ I. Market Returns $\left(\bar{R}_{m}\right)$} \\
\hline \multirow[b]{2}{*}{ Proxy } & \multicolumn{5}{|c|}{ First Three Moments } & \multicolumn{4}{|c|}{ Autocorrelations } & \multicolumn{3}{|c|}{ Index Correlations } \\
\hline & $\mu$ & $\sigma$ & $\mu^{3}$ & $\boldsymbol{W}$ & Prob $<W$ & $\rho_{1}$ & $\rho_{2}$ & $\rho_{3}$ & $\rho_{4}$ & $M 1$ & M2 & M3 \\
\hline VWSTK & .044 & .085 & .692 & .973 & .50 & .05 & -.11 & -.24 & -.09 & 1.00 & & \\
\hline SMI & .036 & .049 & .084 & .984 & .89 & .04 & -.10 & -.17 & -.12 & .95 & 1.00 & \\
\hline USMI & .029 & .026 & -.222 & .980 & .74 & .18 & -.10 & -.28 & -.12 & .90 & .85 & 1.00 \\
\hline MCP & .009 & .011 & -.067 & .983 & .82 & .16 & -.21 & -.12 & .01 & .41 & .27 & .56 \\
\hline
\end{tabular}

II. Transformed Excess Market Returns Used for Kraus-Litzenberger CAPM

\begin{tabular}{|c|c|c|c|c|c|c|c|c|c|c|c|c|}
\hline \multirow[b]{2}{*}{ Proxy } & \multicolumn{5}{|c|}{ First Three Moments } & \multicolumn{4}{|c|}{ Autocorrelations } & \multicolumn{3}{|c|}{ Index Correlations } \\
\hline & $\mu$ & $\sigma$ & $\mu^{3}$ & $W$ & Prob $<W$ & $\rho_{1}$ & $\rho_{2}$ & $\rho_{3}$ & $\rho_{4}$ & Mi & M2 & M3 \\
\hline VWSTK & 2.11 & 8.56 & .609 & .976 & .59 & .07 & -.11 & -.22 & -.09 & 1.00 & & \\
\hline SMI & 1.36 & 5.02 & -.110 & .982 & .79 & .07 & -.09 & -.14 & -.11 & .95 & 1.00 & \\
\hline USMI & 0.70 & 2.70 & -.293 & .978 & .67 & .21 & -.07 & -.23 & -.12 & .91 & .87 & 1.00 \\
\hline
\end{tabular}

Notes:

1. The statistics reported for the MCP portfolio are in real terms. All market proxies are first converted to real terms prior to calculating the correlation coefficients with the MCP. The weights for the MCP portfolio are given in Table 1.

2. Excess returns are transformed as follows:

$$
\tilde{r}_{i}=\left[\frac{\left(\bar{R}_{i}-\tilde{R}_{f}\right)^{*} 100}{\tilde{R}_{f}}\right] \quad \tilde{r}_{M}=\left[\frac{\left(\tilde{R}_{M}-\bar{R}_{j} * 100\right.}{\tilde{R}_{f}}\right]
$$

where $\bar{R}_{i}$ is unity plus the return on the ith risky asset $i=1, \ldots, m$ and $\bar{R}_{f}$ is unity plus the return on the riskless rate. Sample autocorrelations are estimated as regression coefficients. The asymptotic standard error of $\rho_{\tau}$ is .15 under the hypothesis that the true autocorrelations are all equal to zero for the period 1979Q1-1989Q4. Autocorrelation is statistically significant if it is more than two standard errors: for example, greater than $\rho_{3}>.30$.

\subsection{Details of test}

The multivariate approach used in this study is similar to that of Gibbons (1982) and BaroneAdesi (1985). Model estimation proceeds after the number of assets is first reduced to a smaller

\footnotetext{
${ }^{10}$ The Shapiro-Wilk (1965) W statistic is used to investigate whether the return distribution is normal. The maximum value of $\boldsymbol{W}$ is $\mathbf{1}$, with values near $\mathbf{1}$ indicative of normality. Percentage points associated with the critical $\boldsymbol{W}$ region are reported in this study as Prob $<\boldsymbol{W}$. Shapiro and Wilk use a Prob $<\boldsymbol{W}$ of 50 percent or greater to evidence normality.
} 
number of portfolios to increase the power of the tests and also to avoid a singular covariance matrix of residuals.

Nine mutually exclusive portfolios consisting of four portfolios of common stocks and five CREFs are constructed to test the CAPM and its various modifications. For all two moment CAPMs, the beta for each stock is first calculated using the single-index model. The resulting betas are next ranked in descending order of magnitude and then four quartiles are formed based on the rank-sorted betas. The stocks in each quartile are grouped into a portfolio. For tests of the K-L three-moment CAPM, assets are classified into portfolios with respect to the $\boldsymbol{c}_{1 i}$ and $\boldsymbol{c}_{\mathbf{2 i}}$ coefficients as in Barone-Adesi (1985). First, the $\boldsymbol{c}_{\mathbf{1 i}}$ and $\boldsymbol{c}_{\mathbf{2} i}$ coefficients for each stock is estimated using the quadratic index model in equation (1). Next, the $\boldsymbol{c}_{\mathbf{1 i}} \mathrm{S}$ are ranked in descending order of magnitude, and then the stocks corresponding to these rank-sorted $\boldsymbol{c}_{\mathbf{1 i}} \mathrm{S}$ are split into two groups. Each of the two $\boldsymbol{c}_{\mathbf{1 i}}$ stock groups is next subdivided into two portfolios based on each stock's $\boldsymbol{c}_{2 i}$ estimate with the $\boldsymbol{c}_{2 i}$ s also ranked in descending order of magnitude. This results in four stock portfolios. Five CREFs are used for the real estate funds. Equally weighted stock portfolios are formed after the stocks are categorized into groups with the return computed for each portfolio. Each of the resulting portfolio return series is tested for the autocorrelation of a series.

To test the null hypothesis in equation (5) for the K-L CAPM (or, alternatively, equation (9) for the zero beta CAPM and CCAPM, and equation (7) for the traditional CAPM), two alternative sets of estimators associated with the system of nine regression equations (one equation per portfolio) are estimated using an iterative nonlinear seemingly unrelated regression (ITNLSUR) model. Like the generalized method of moments (GMM) that Lim (1989) uses, the ITNLSUR does not impose strong distributional assumptions on the asset returns. ${ }^{11}$ This technique (c.f. Gallant, 1975) involves a one-step Gauss-Newton procedure. One set of parameters is estimated unconstrained using the model in equation (1) (or, alternatively, equation (10) for the traditional CAPM and equation (12) for either the zero beta CAPM or CCAPM) while the other set of parameters is restricted with the model in equation (4) (or, alternatively, equation (11) for the traditional CAPM and equation (13) for either the zero beta CAPM or CCAPM) used to estimate these restricted coefficients. Two likelihood ratio statistics (LRT), one based on the chi-square distribution and the other based on the F distribution, with a Jobson-Korkie (1982) adjustment for small sample size are used to compare the statistical "fit" of the constrained model in equation (4) [(11), (13)] with that of the unconstrained model in equation (1) [(10), $(12)]$.

\footnotetext{
${ }^{11}$ Gallant and Holly (1980), Gallant and Jorgensen (1979), and Gallant (1987) have shown that ITNLSUR estimators are strongly consistent and are asymptotically normal even if the error distribution departs from normality. Furthermore, ITNLSUR yield full-information MLEs if the errors are multivariate normal.
} 
Since the CREF returns are based on appraised values, an $A R(4)$ correction is used in the ITNLSUR estimation process to adjust for smoothing. Modeling CREF returns as an AR(4) process is equivalent to the smoothing correction procedure discussed in Firstenberg, Ross, and Zisler (1988). The proof of this is shown in Appendix D.

\section{Empirical results}

Table 3 reports on the statistical properties associated with the quarterly returns for the portfolios of stocks and CREFs grouped according to section 3.1. Table 3 shows that none of the CREF returns are normally distributed even after these returns are adjusted for smoothing. All CREFs exhibit positive excess skewness (except when CREF 2 is transformed) which is consistent with the findings of McCue (1984). In addition to this, the returns on three of the five CREFs possess fourth order autocorrelation. The magnitude of these autocorrelations diminish when the CREF returns are transformed. Of interest is that one insurance-company-sponsored CREF (CREF 3) and one bank-sponsored CREF (CREF 5) exhibit no autocorrelation at any lag. By design, no CREF exhibits autocorrelation after a correction is made for smoothing. In contrast to 
Table 3. Statistics on asset portfolios.

\begin{tabular}{|c|c|c|c|c|c|c|c|c|c|}
\hline \multicolumn{10}{|c|}{ Cref Returns Not Adjusted for Smoothing } \\
\hline \multirow[b]{2}{*}{ Fund } & \multicolumn{5}{|c|}{ First Three Moments } & \multicolumn{4}{|c|}{ Autocorrelations } \\
\hline & $\mu$ & $\sigma$ & $\mu^{3}$ & $w$ & Prob $<W$ & $\rho_{1}$ & $\rho_{2}$ & $\rho_{3}$ & $\rho_{4}$ \\
\hline \multicolumn{10}{|c|}{ I. Cref Returns $\left(\bar{R}_{i}\right)$} \\
\hline $\begin{array}{l}\text { Cref1 } \\
\text { Cref2 } \\
\text { Cref3 } \\
\text { Cref4 } \\
\text { Cref5 }\end{array}$ & $\begin{array}{l}.024 \\
.022 \\
.026 \\
.027 \\
.027\end{array}$ & $\begin{array}{l}.011 \\
.019 \\
.012 \\
.017 \\
.033\end{array}$ & $\begin{array}{r}1.00 \\
.93 \\
2.20 \\
1.18 \\
2.40\end{array}$ & $\begin{array}{l}.921 \\
.917 \\
.839 \\
.907 \\
.706\end{array}$ & $\begin{array}{l}<.01^{*} \\
<.01^{*} \\
<.01^{*} \\
<.01^{*} \\
<.01^{*}\end{array}$ & $\begin{array}{l}.597^{*} \\
.462^{*} \\
.252 \\
.672^{*} \\
.185\end{array}$ & $\begin{array}{l}.736^{*} \\
.465^{*} \\
.274 \\
.531^{*} \\
.035\end{array}$ & $\begin{array}{l}.486^{*} \\
.372^{*} \\
-.049 \\
.528^{*} \\
.003\end{array}$ & $\begin{array}{l}.398^{*} \\
.396^{*} \\
.053 \\
.382^{4} \\
.053\end{array}$ \\
\hline $\begin{array}{l}\text { II. Tra } \\
\text { Cref1 } \\
\text { Cref2 } \\
\text { Cref3 } \\
\text { Cref4 } \\
\text { Cref5 }\end{array}$ & $\begin{array}{l}.178 \\
.030 \\
.0317 \\
.446 \\
.468\end{array}$ & $\begin{array}{l}\text { ss Cref } \\
.82 \\
1.66 \\
1.13 \\
1.41 \\
2.93\end{array}$ & $\begin{array}{r}\text { turns } \\
1.35 \\
-1.00 \\
2.75 \\
1.44 \\
2.00\end{array}$ & $\begin{array}{l}.877 \\
.877 \\
.847 \\
.791 \\
.895 \\
.743\end{array}$ & $\begin{array}{c}\text { us-Litzenbe } \\
<.01^{*} \\
<.01^{*} \\
<.01^{*} \\
<.01^{*} \\
<.01^{*}\end{array}$ & $\begin{array}{l}\text { CAPM } \\
.041 \\
.278 \\
.020 \\
.576^{*} \\
.076\end{array}$ & $\begin{array}{l}.351^{*} \\
.362^{*} \\
.166 \\
.356 * \\
-.043\end{array}$ & $\begin{array}{c}.208 \\
.228 \\
-.186 \\
.364^{*} \\
-.094\end{array}$ & $\begin{array}{r}-.066 \\
.228 \\
.054 \\
.297 \\
-.004\end{array}$ \\
\hline
\end{tabular}

Cref Returns Adjusted for Smoothing Using the Ross-Zisler Method

\begin{tabular}{llllllllll}
\hline \multicolumn{2}{l}{ I. Cref Returns $\left(\bar{R}_{i}\right)$} & & & & & & & \\
Cref1 & .021 & .034 & 1.01 & .916 & $<.01^{*}$ & .000 & .054 & .008 & -.250 \\
Cref2 & .056 & .169 & .32 & .947 & $.07^{*}$ & .002 & -.041 & -.061 & -.111 \\
Cref3 & .025 & .020 & 2.33 & .833 & $<.01^{*}$ & -.077 & -.148 & .040 & -.018 \\
Cref4 & .022 & .050 & 1.07 & .918 & $<.01^{*}$ & .025 & -.225 & .100 & .089 \\
Cref5 & .026 & .049 & 2.40 & .742 & $<.01^{*}$ & -.105 & -.071 & -.002 & -.187
\end{tabular}

I. Transformed Excess Cref Retums Used for Kraus-Litzenberger CAPM

\begin{tabular}{lrrrrrrrrr} 
Cref1 & -.11 & 3.26 & .82 & .940 & $.04 *$ & .061 & .094 & .000 & .000 \\
Cref2 & 3.22 & 16.70 & .32 & .949 & $.08^{*}$ & -.011 & -.045 & -.068 & -.124 \\
Cref3 & .27 & 1.75 & 2.62 & .803 & $<.01^{*}$ & .024 & -.087 & .088 & -.016 \\
Cref4 & .04 & 4.78 & .95 & .926 & $.01^{*}$ & .012 & -.230 & .106 & .067 \\
Cref5 & .35 & 4.46 & 2.15 & .780 & $<.01^{*}$ & -.033 & -.035 & .034 & -.147 \\
\hline
\end{tabular}

\begin{tabular}{|c|c|c|c|c|c|c|c|c|c|c|}
\hline \multirow[b]{2}{*}{ Proxy } & \multirow[b]{2}{*}{ Fund } & \multicolumn{5}{|c|}{ First Three Moments } & \multicolumn{4}{|c|}{ Autocorrelations } \\
\hline & & $\mu$ & $\sigma^{2}$ & $\mu^{3}$ & $W$ & Prob $<W$ & $\rho_{1}$ & $\rho_{2}$ & $D_{3}$ & $\rho_{4}$ \\
\hline \multicolumn{11}{|c|}{ 1. Stock Returns $\left(\tilde{R}_{i}\right)$} \\
\hline VWSTK & $\begin{array}{l}\text { Stock1 } \\
\text { Stock2 } \\
\text { Slock3 } \\
\text { Stock4 }\end{array}$ & $\begin{array}{l}.054 \\
.044 \\
.047 \\
.051\end{array}$ & $\begin{array}{l}.129 \\
.104 \\
.091 \\
.071\end{array}$ & $\begin{array}{l}.15 \\
.24 \\
.46 \\
.99\end{array}$ & $\begin{array}{l}982 \\
.983 \\
.981 \\
.943\end{array}$ & $\begin{array}{l}.80 \\
.85 \\
.75 \\
.05 *\end{array}$ & $\begin{array}{r}.013 \\
.118 \\
.059 \\
-.019\end{array}$ & $\begin{array}{l}-.119 \\
-.214 \\
-.125 \\
-.175\end{array}$ & $\begin{array}{l}-.236 \\
-.200 \\
-.125 \\
-.111\end{array}$ & $\begin{array}{l}-.055 \\
-.079 \\
-.181 \\
-.065\end{array}$ \\
\hline SMI & $\begin{array}{l}\text { Stock1 } \\
\text { Stock2 } \\
\text { Stock3 } \\
\text { Stock4 }\end{array}$ & $\begin{array}{l}.055 \\
.044 \\
.046 \\
.051\end{array}$ & $\begin{array}{l}.128 \\
.104 \\
.089 \\
.073\end{array}$ & $\begin{array}{l}.27 \\
.26 \\
.68 \\
.65\end{array}$ & $\begin{array}{l}.985 \\
.982 \\
.969 \\
.965\end{array}$ & $\begin{array}{l}.90 \\
.79 \\
.42^{*} \\
.34^{*}\end{array}$ & $\begin{array}{r}.036 \\
.096 \\
.034 \\
-.004\end{array}$ & $\begin{array}{l}-.172 \\
-.154 \\
-.170 \\
-.129\end{array}$ & $\begin{array}{l}-.225 \\
-.164 \\
-.218 \\
-.130\end{array}$ & $\begin{array}{l}-.023 \\
-.131 \\
-.072 \\
-.144\end{array}$ \\
\hline USMI & $\begin{array}{l}\text { Stock1 } \\
\text { Stock2 } \\
\text { Stock3 } \\
\text { Stock4 }\end{array}$ & $\begin{array}{l}.054 \\
.043 \\
.049 \\
.049\end{array}$ & $\begin{array}{l}.129 \\
.105 \\
.093 \\
.071\end{array}$ & $\begin{array}{r}.27 \\
.02 \\
.42 \\
-1.00\end{array}$ & $\begin{array}{l}.983 \\
.980 \\
.980 \\
.941\end{array}$ & $\begin{array}{l}.83 \\
.73 \\
.73 \\
.04 *\end{array}$ & $\begin{array}{r}.041 \\
.109 \\
.065 \\
-.003\end{array}$ & $\begin{array}{l}-.151 \\
-.060 \\
-.247 \\
-.138\end{array}$ & $\begin{array}{l}-.185 \\
-.217 \\
-.139 \\
-.117\end{array}$ & $\begin{array}{l}-.033 \\
-.155 \\
-.082 \\
-.064\end{array}$ \\
\hline
\end{tabular}


Table 3 (Cont.)

\begin{tabular}{|c|c|c|c|c|c|c|c|c|c|c|}
\hline \multirow[b]{2}{*}{ Proxy } & \multirow[b]{2}{*}{ Fund } & \multicolumn{5}{|c|}{ First Three Moments } & \multicolumn{4}{|c|}{ Autocorrelations } \\
\hline & & $\mu$ & $\sigma^{2}$ & $\mu^{3}$ & $\boldsymbol{W}$ & Prob $<W$ & $\rho_{1}$ & $\rho_{2}$ & $\rho_{3}$ & $\rho_{4}$ \\
\hline \multicolumn{11}{|c|}{ D. Tranşoormed Excess Stock Returns Used for Kraus-Litzenberger CAPM } \\
\hline VWSTK & $\begin{array}{l}\text { Stock1 } \\
\text { Stock2 } \\
\text { Stock3 } \\
\text { Stock4 }\end{array}$ & $\begin{array}{l}2.66 \\
2.71 \\
2.19 \\
2.93\end{array}$ & $\begin{array}{r}11.87 \\
11.50 \\
8.86 \\
7.59\end{array}$ & $\begin{array}{r}.39 \\
.42 \\
.16 \\
-1.00\end{array}$ & $\begin{array}{l}.976 \\
.977 \\
.989 \\
.917\end{array}$ & $\begin{array}{r}.63 \\
.65 \\
.97 \\
<.01^{*}\end{array}$ & $\begin{array}{l}.076 \\
.037 \\
.062 \\
.005\end{array}$ & $\begin{array}{l}-.106 \\
-.209 \\
-.163 \\
-.080\end{array}$ & $\begin{array}{l}-.193 \\
-.177 \\
-.118 \\
-.132\end{array}$ & $\begin{array}{r}-.154 \\
.013 \\
-.146 \\
-.008\end{array}$ \\
\hline SMI & $\begin{array}{l}\text { Stock1 } \\
\text { Stock2 } \\
\text { Stock3 } \\
\text { Stock4 }\end{array}$ & $\begin{array}{l}2.90 \\
2.66 \\
2.10 \\
2.82\end{array}$ & $\begin{array}{r}11.90 \\
11.16 \\
8.24 \\
8.15\end{array}$ & $\begin{array}{r}.25 \\
.45 \\
.10 \\
-1.20\end{array}$ & $\begin{array}{l}.985 \\
.980 \\
.987 \\
.929\end{array}$ & $\begin{array}{l}.91 \\
.74 \\
.94 \\
.02 *\end{array}$ & $\begin{array}{l}.122 \\
.017 \\
.056 \\
.010\end{array}$ & $\begin{array}{l}-.162 \\
-.213 \\
-.136 \\
-.080\end{array}$ & $\begin{array}{l}-.202 \\
-.155 \\
-.138 \\
-.180\end{array}$ & $\begin{array}{r}-.171 \\
-.037 \\
-.146 \\
.011\end{array}$ \\
\hline USMI & $\begin{array}{l}\text { Stock1 } \\
\text { Stock2 } \\
\text { Stock3 } \\
\text { Stock4 }\end{array}$ & $\begin{array}{l}2.98 \\
2.22 \\
2.43 \\
2.86\end{array}$ & $\begin{array}{r}11.24 \\
12.40 \\
8.62 \\
7.69\end{array}$ & $\begin{array}{r}.23 \\
-.22 \\
.24 \\
-1.20\end{array}$ & $\begin{array}{l}.981 \\
.979 \\
.980 \\
.916\end{array}$ & $\begin{array}{r}.78 \\
.71 \\
.74 \\
<.01 *\end{array}$ & $\begin{array}{l}.106 \\
.014 \\
.069 \\
.019\end{array}$ & $\begin{array}{l}-.112 \\
-.114 \\
-.213 \\
-.072\end{array}$ & $\begin{array}{l}-.196 \\
-.181 \\
-.096 \\
-.108\end{array}$ & $\begin{array}{l}-.152 \\
-.014 \\
-.049 \\
-.038\end{array}$ \\
\hline
\end{tabular}

this, most of the returns on stock portfolios are normally distributed except for the last stock fund (stock 4) associated with each market proxy. Besides this, the first four sample autocorrelations of the returns on the stock portfolios for each market proxy are generally close to zero at all lags. Table 3 also reveals that the returns and standard deviations on CREFs are lower than those for stocks, but the magnitude of total positive excess skewness is higher for CREFs relative to stocks.

However, this evidence does not imply that skewness is priced nor that skewness is responsible for the relative performance of real estate versus stocks since only total skewness and not systematic skewness is reported in Table 3. The only way to ascertain if skewness is incorporated in the market pricing of assets is through the use of an equilibrium model such as the Kraus-Litzenberger (K-L) CAPM. Table 4 summarizes the results for the K-L CAPM as well as the results for alternative two-moment versions of the CAPM. Each model is tested over the period from the first quarter of 1979 to the fourth quarter of 1989 using nine portfolios. In the last two columns of Table 4, the likelihood ratio tests (LRT) associated with the various CAPM hypotheses are reported. The chi-square and $\mathrm{F}$ statistics in Table 4 show that the restriction implied by each version of the CAPM is not rejected at reasonable significance levels (10 percent, 5 percent, or 1 percent). Therefore, our likelihood ratio tests (LRT) are unable to distinguish between the alternative versions of the CAPM. This is due in part to the smaller sample size used in our study $(T=44)$ compared to the impact of small sample sizes $(T>60)$ on the LRT statistics that Jobson and Korkie (1982) studied. In addition to this, it was noted earlier that acceptance of the two-moment CAPM also implies that the three-moment CAPM holds. However, it is interesting to note that the magnitude of both LRT statistics is the lowest for the K-L CAPM, followed by zero beta CAPM of Black, the consumption-oriented CAPM, and finally the traditional CAPM when the USMI proxy is used. We will therefore compare the alternative 
CAPM models based on the sign of the appropriate coefficient and corresponding t-statistic which each model should exhibit if the appropriate capital market theory holds.

Table 4. Iterated nonlinear seemingly unrelated regression with AR(4) autocorrelation correction AR(4) estimated using conditional least-squares method.

The $\chi^{2}$ and $F$ statistics reported test whether the restriction on the intercept term in the following sets of equations hold using iterated nonlinear SUR for the respective CAPMs.

I. Sharpe-Litner-Mossin CAPM

Unurestricted: $\tilde{R}_{i}-r_{f}=\alpha_{i}+\beta_{j}\left(\tilde{R}_{M}-r_{j}+\tilde{e}_{i} \quad i=1, \ldots, N\right.$

Restricted: $\quad \tilde{R}_{i}-r_{f}=\gamma+\beta_{i}\left(\tilde{R}_{M}-r_{j}+\tilde{e}_{i} \quad i=1, \ldots, N\right.$ where $\gamma=0$

II. Black's Zero Beta CAPM (also used to test Consumption CAPM using the MCP portfolio in real tems) Unrestricted: $\tilde{R}_{i}=\alpha_{i}+\beta_{i} \bar{R}_{M}+\bar{e}_{i} \quad i=1, \ldots, N$

Restricted: $\quad \bar{R}_{i}=\gamma\left(1-\beta_{i}\right)+\beta_{i} \bar{R}_{M}+\bar{e}_{i} \quad i=1, \ldots, N \quad$ where $\gamma>0$ and $\gamma>r_{f}$

III. Kraus-Litzenberger Three-Moment CAPM

Unrestricted: $\tilde{R}_{j}-R_{F}=c_{0 i}+c_{1 i}\left(\tilde{R}_{M}-R_{F}\right)+c_{2}\left(\tilde{R}_{H}-\bar{R}_{M}\right)^{2}+\tilde{e}_{i} \quad i=1, \ldots, N$

Restricted: $\quad \vec{R}_{i}-R_{F}=c_{2 i} \sigma_{M}^{2}\left(2 b_{3} \sigma_{M}^{2}-1\right)+c_{1 i}\left(\bar{R}_{M}-R_{F}\right)+c_{2 i}\left(\tilde{R}_{M}-\tilde{R}_{M}\right)^{2}+\tilde{e}_{i} \quad$ where $b_{3}<0$

J. Test of the Sharpe-Litner-Mossin CAPM

\begin{tabular}{lccccr} 
Proxy & $\gamma$ & $T(\gamma)$ & Pr $>|T|$ & $\chi_{8}^{2}$ & F(8, 34) \\
\hline VWSTK & .0049 & 3.16 & .003 & 6.9065 & .8471 \\
SMI & .0037 & 2.24 & .030 & 6.8955 & .8456 \\
USMI & .0039 & 2.89 & .006 & 6.9057 & .8470 \\
\hline
\end{tabular}

1I. Test of Black's Zero Beta CAPM (Test of CCAPM uses MCP Portfolio)

\begin{tabular}{lcccccr} 
Proxy & $\bar{r}_{f}$ & $\gamma=\bar{r}_{z}$ & $T(\gamma)$ & $\operatorname{Pr}>|T|$ & $\chi_{8}^{2}$ & $F(8,34)$ \\
\hline VWSTK & .0224 & .0268 & 13.12 & .000 & 6.9050 & .8469 \\
SMl & .0224 & .0271 & 11.75 & .000 & 6.8970 & .8458 \\
USMl & .0224 & .0244 & 15.06 & .000 & 6.8947 & .8455 \\
MCP & .0081 & .0103 & 7.72 & .000 & 6.9054 & .8469 \\
\hline
\end{tabular}

III. Test of Kraus-Litzenberger's 3 Moment CAPM

\begin{tabular}{lrrrrrrr} 
Proxy & $b_{3}$ & $\mathrm{~T}\left(b_{3}\right)$ & Pr $>|T|$ & $\chi_{8}^{2}$ & $\mathbf{F}(8,34)$ & Stock $\bar{m}_{i M M}$ & Cref $\bar{m}_{i M M}$ \\
\hline VWSTK & -.000088 & -3.83 & .00 & 6.9004 & .8463 & 1.69 & -30.94 \\
SMI & -.000127 & -2.18 & .03 & 6.9054 & .8469 & -28.98 & -7.37 \\
USMI & -.000357 & -2.75 & .01 & 6.8848 & .8442 & -3.92 & -0.34 \\
\hline
\end{tabular}

Note: The critical levels of $\chi_{\mathrm{B}}^{2}$ are $p(.10)=13.362, \mathrm{p}(.05)=15.507, p(.01)=20.090$ while the critical level for $\mathrm{F}_{8,34}$ is $p(.95)=2.25$. The $m_{i M M}=2 c_{2 i} \sigma_{M}^{2}$ reported is calculated using the restricted regression parameter estimates for $c_{2 i}$. As an alternative to using an AR(4) process, the CREF returns were adjusted for smoothing prior to the estimation process with no significant change in the parameter estimales although the standard errors are slightly higher.

The tests of the traditional CAPM in Table 4 reveals that the intercept term $(\gamma)$ is significandy different from zero with respect to all three market proxies even though the magnitude of $\gamma$ is close to zero which is contrary to that hypothesized if the traditional CAPM holds. In contrast to this, the $\gamma$ parameter estimate in tests of the zero beta CAPM appear to be consistent with theory. Not only is $\gamma$ significantly greater than zero but the return on the riskfree surrogate is also greater than the average return on the three month Treasury bill. This finding thus 
supports the results of Liu and associates (1990b). The return data are also' consistent with the theory underlying the consumption-oriented CAPM when a riskless asset is not observed. Both $\boldsymbol{\gamma}>\mathbf{0}$ and $\boldsymbol{\gamma}>\boldsymbol{r}_{\boldsymbol{f}}$ in real terms, thus substantiating the conjecture of Geltner (1989) that the CCAPM should hold for real estate data. In addition to the parameters having the correct sign for the preceding nonstandard two-moment CAPMs, the sign of the skewness parameter $\boldsymbol{b}_{\mathbf{3}}$ in the test of the K-L CAPM also conforms to the skewness theory that $\boldsymbol{b}_{\mathbf{3}}<\mathbf{8 0}$ under the assumption of decreasing absolute risk aversion when equation (3) is the correct model. The parameter $\boldsymbol{b}_{\mathbf{3}}$ is negative and significant for all market proxies. Moreover, the magnitude of the risk premium associated with systematic skewness $\left(\boldsymbol{b}_{\mathbf{3}}\right)$ increases as more asset classes are included in the market proxy. Specifically, $\boldsymbol{b}_{\mathbf{3}}$ takes on a more negative value as the $\mathrm{SMI}$ is substituted for the VWSTK and the USMI proxy replaces the SMI as the market proxy. The K-L CAPM results in Table 4 are also consistent with the observation made with respect to Table 3 that returns on CREFs are less than the returns on stocks because Table 4 shows that the average systematic co-skewness value, $\boldsymbol{m}_{\boldsymbol{i} \boldsymbol{M} \boldsymbol{M}}$, for real estate is higher (less negative) than that for stocks except when a value-weighted stock market proxy is used. Consequently, if we compare mean excess returns and adjust only for systematic risk (beta) but neglect systematic co-skewness, it will appear that the risk-return relationship between real estate and stocks in incongruous. This incongruity arises because we are not recognizing that investors are satisfied with a lower mean excess return on real estate relative to stock given that positive portfolio coskewness or less negative co-skewness is desirable to investors (after adjusting for variance risks and assuming that the return on the market portfolio is normally distributed) and the magnitude of negative co-skewness is smaller for real estate compared to stocks.

The invariance in the sign and significance of the parameters across alternative market proxies in the aforementioned tests of the CAPM are in accord with the conclusions of Stambaugh (1982). The fact that the skewness premium $\left(\boldsymbol{b}_{3}\right)$ is significant when the market proxy chosen consists of stocks and bonds (SMI) is in contrast to the finding in Friend and Westerfield (1980) that the premium for systematic skewness in quarterly stock returns is not significant when a value-weighted common stock and bond index is employed (see Table in in Friend and Westerfield, 1980, p. 905). The results in this study also confirm the findings of previous studies (Kraus and Litzenberger, 1976; Barone-Adesi, 1985; Sears and Wei, 1988; and Lim, 1989)-that skewness is priced when the market proxy chosen consists solely of stocks. The skewness premium $\boldsymbol{b}_{\mathbf{3}}$ for stocks in the current study is significant at the 5 percent level of significance when the VWSTK proxy is used.

\section{Summary and conclusions}

The current study investigates whether the recognition of systematic skewness can offer an alternative perspective as to why the risk-adjusted returns on real estate should be similar to 
that for stocks. This is not a trivial issue since an affirmative finding of systematic skewness implies that we are not considering an important ingredient in the measurement of real estate risk. It also suggests that the Firstenberg, Ross, and Zisler (1988) story on real estate might require a sequel, namely that three moments are important in the portfolio formation process. A multivariate test of the Kraus-Litzenberger model is used to investigate this positive coskewness proposition with the K-L CAPM tested against several alternative two moment versions of the CAPM. With respect to the Kraus-Litzenberger version of the CAPM, not only is the sign of the skewness parameter negative and significant but also the average systematic coskewness value for real estate is less negative than that for stocks in general. This evidence is consistent with our proposition that investors are satisfied with a lower mean excess return on real estate relative to stock given that positive portfolio co-skewness or less negative coskewness is desirable to investors and the magnitude of negative co-skewness is smaller for real estate compared to stocks. Since the K-L CAPM represents an alternative explanation to the zero beta CAPM, it is not surprising that both the zero beta CAPM and the consumptionoriented CAPM are also found to hold.

Several avenues for future research arise from this study. The first involves the extent to which systematic skewness might affect the mixed-asset portfolio allocation decision given our finding that systematic skewness is relevant in the pricing of CREF returns. Another issue not addressed in our study is whether this skewness persists over time. A final issue that remains for future research involves whether actual, transactions-based real estate returns are also positively skewed.

\section{Acknowledgments}

The authors would like to thank Stephen Brown, Roy Gilbert, Wylie Greig, David Guilkey, Larry Lang, and Steve Smith for constructive comments on earlier drafts of this article and Evaluation Associates for providing data. The authors would also like to thank two anonymous reviewers whose comments substantially improved the quality of the article.

\section{Appendix A: The Property or Stock Associated with Each General Asset Category}

Commercial Real Estate: Type: Three insurance CREFs (CREF 1, CREF 3, and CREF 4) and two bank CREFs (CREF 2 and CREF 5).

S\&P500 Stock Industry Groups: Aerospace, Aluminum, Auto Parts-After Market, Automobiles, Automobiles-Trucks, Beverages-Brewers, Beverages-Soft Drinks, Broadcast Media, Building 
Materials, Chemicals, Coal, Computers, Conglomerates, Containers-Metal, Containers-Paper, Cosmetics, Drugs, Electrical Equipment, Electronics-Instrument, Electronics-Semiconductor, Entertainment, Financial, Foods, Gold Mining, Homebuilding, Hospital Management, Hospital Supplies, Hotel \& Motel, Household Appliances, Leisure Time, Machine Tools, MachineryIndustrial, Metals-Miscellaneous, Mobile Homes, Offshore Drilling, Oil Composite, Oil Well Equipment and Services, Pollution Control, Publishing, Publishing-Newspapers, Restaurants, Retail Stores-Composite, Shoes, Steel, Textile-Apparel Manufacturing, Tobacco, Toys, Transportation, and Utilities.

\section{Appendix B: The Way in which the Return and Market Value Associated with each Asset Class Used to Construct the Portfolio Return and Portfolio Weights in Table 1 are Obtained}

1. Cash Equivalents. Returns on Treasury-bills with a three-month maturity are from issues of Economic Indicators. Yields and market values on 90- to 119-day commercial paper, 90-day bankers' acceptances, and values for three-month Treasury-bills are from the Federal Reserve Bulletin.

2. Bonds. Returns and aggregate market values on bonds are obtained from the ShearsonLehmann publication, The Bond Market Annual Report.

3. Common Stock. The return and market value are from the CRSP tapes for all common stocks on the NYSE, AMEX, and NASDAQ.

4. Commercial Real Estate. Aggregate value estimates for nonresidential commercial real estate structures are taken from Musgrave (1981) and subsequent issues of the Survey of Current Business. The series for current dollar net stock of noncorporate nonresidential structures is chosen to avoid double counting corporate real estate. Farm structures are factored out from this total. The aggregate land value is obtained from the Board of Governors of the Federal Reserve System publication, Balance Sheets for the U.S.Economy 1945-1990. The mortgage amount outstanding for nonresidential income producing properties taken from the Federal Reserve's Annual Statistical Series is subtracted from the total market value to yield the equity value.

The Evaluation Associates (EAI) CREF index is used as a proxy for commercial real estate returns. The EAI return series is adjusted for smoothing using the technique in Firstenberg, Ross, and Zisler (1988) with a four-quarter lag. 
5. Farm Real Estate. Farm returns are from the Federal Reserve Bank of Kansas City. ${ }^{12}$ Income and the market vaue of farms are obtained from the U.S. Department of Agriculture publications, Farm Real Estate Market Developments: Outlook and Situaton, Agricultural

Land Values and Markets, and Agricultural Resources: Outlook and Situation Summary. Real estate debt reported in Economic Indicators of the Farm Sector: National Financial Summary 1990 is subtracted from total farm value to generate total farm equity. The farm return series, like the EAl series, is adjusted for smoothing.

6. Single-Family Homes. The new one-family houses sold price index, which is a quality-adjusted hedonic index (HNPRR) from CITIBASE, is used to measure the price appreciation of a standard home. Monthly median rents, vacancies, and operating expenses are obtained from the U.S. Bureau of the Census publication, Annual Housing Survey: Summary of Housing Characteristics for Selected Metropolitan Areas, $\mathrm{H}-171$ Series. Aggregate values are taken from Balance Sheets for the U.S. Economy 1945-1990. The aggregate home mortgage debt quoted in the Federal Reserve publication, Annual Statistical Series, is subtracted from this total to obtain home equity.

\section{Appendix C: Derivation of the Restriction on the Intercept for the Kraus-Litzenberger CAPM}

The characteristic line that Kraus and Litzenberger use for their three-moment CAPM is:

$$
\tilde{R}_{i}-R_{F}=c_{0 i}+c_{1 i}\left(\bar{R}_{M}-R_{F}\right)+c_{2 i}\left(\bar{R}_{M}-\bar{R}_{M}\right)^{2}+\bar{e}_{i}
$$

where $\boldsymbol{E}\left(\overline{\boldsymbol{e}}_{\boldsymbol{i}}\right)=\mathbf{0}, \boldsymbol{E}\left[\overline{\boldsymbol{e}}_{\boldsymbol{i}}\left(\widetilde{\boldsymbol{R}}_{\boldsymbol{M}}-\boldsymbol{R}_{\boldsymbol{F}}\right)\right]=\mathbf{0}, \boldsymbol{E}\left[\overline{\boldsymbol{e}}_{\boldsymbol{i}}\left(\widetilde{\boldsymbol{R}}_{\boldsymbol{M}}-\overline{\boldsymbol{R}}_{\boldsymbol{M}}\right)\right]=\mathbf{0}$, and $\boldsymbol{E}\left[\overline{\boldsymbol{e}}_{\boldsymbol{i}}\left(\widetilde{\boldsymbol{R}}_{\boldsymbol{M}}-\right.\right.$ $\left.\left.\overline{\boldsymbol{R}}_{M}\right)^{2}\right]=\mathbf{0}$. Taking the expected value of equation (A. 1) and then subtracting this result from equation (A.I) yields

$$
\left(\tilde{R}_{i}-\bar{R}_{i}\right)=c_{1 i}\left(\tilde{R}_{M}-\bar{R}_{M}\right)+c_{2 i}\left\{\left(\tilde{R}_{M}-\bar{R}_{M}\right)^{2}-E\left[\left(\tilde{R}_{M}-\tilde{R}_{M}\right)^{2}\right]\right\}+\tilde{e}_{i}
$$

Multiplying both sides of equation (A.2) by $\left(\widetilde{\boldsymbol{R}}_{\boldsymbol{M}}-\overline{\boldsymbol{R}}_{\boldsymbol{M}}\right)$, taking expected values and then dividing through by $\sigma_{M}^{2}$ yields an expression for the beta of the ith risky asset

$$
\beta_{i M}=c_{1 i}+c_{2 i}\left(m_{M}^{3} / s_{M}^{2}\right)
$$

where $\boldsymbol{m}_{\boldsymbol{M}}^{\mathbf{3}}=\boldsymbol{E}\left\{\left(\widetilde{\boldsymbol{R}}_{\boldsymbol{M}}-\overline{\boldsymbol{R}}_{\boldsymbol{M}}\right)^{\mathbf{3}}\right\}$. Next, if $\left(\widetilde{\boldsymbol{R}}_{\boldsymbol{M}}-\overline{\boldsymbol{R}}_{\boldsymbol{M}}\right.$ is multiplied on both sides of equation (A.2) and then expectations are taken on both the right- and left-hand side of the resulting equation, then this yields

\footnotetext{
12 The Federal Reserve Bank of Kansas City is the only federal reserve bank that has continuous price data on farm real estate over the study period. The price of farmland for the appropriate states under the jurisdiction of other federal reserve banks such as the Federal Reserve Bank of Dallas are of more recent origin (1985).
} 


$$
m_{i M M}=c_{1 i} m_{M}^{3}+c_{2 i}\left[k_{M}^{4}-\sigma_{M}^{4}\right]
$$

where $\boldsymbol{m}_{\boldsymbol{i} M \boldsymbol{M}}=\boldsymbol{E}\left\{\left(\widetilde{\boldsymbol{R}}_{\boldsymbol{i}}-\overline{\boldsymbol{R}}_{\boldsymbol{i}}\right)\left(\widetilde{\boldsymbol{R}}_{\boldsymbol{M}}-\overline{\boldsymbol{R}}_{M}\right)^{2}\right\}, \boldsymbol{m}_{M}^{3}=\boldsymbol{E}\left\{\left(\widetilde{\boldsymbol{R}}_{M}-\overline{\boldsymbol{R}}_{M}\right)^{3}\right\}$, and $\boldsymbol{k}_{M}^{4}=$ $\boldsymbol{E}\left\{\left(\widetilde{\boldsymbol{R}}_{\boldsymbol{M}}-\overline{\boldsymbol{R}}_{\boldsymbol{M}}\right)^{4}\right\}$. If the rate of return on the market portfolio is symmetrically distributed $\widetilde{R}_{M} \sim \boldsymbol{N}\left(\mu, \sigma^{2}\right)$, then $\boldsymbol{m}_{M}^{3}=\mathbf{0}$ and $\boldsymbol{m}_{M}^{3}=\mathbf{3} \sigma_{M}^{4}$ so equation (A.3) and equation (A.4) degenerate, respectively, to ${ }^{13}$

$$
\begin{aligned}
& \beta_{i M}=c_{1 i} \\
& m_{i M M}=2 c_{2 i} \sigma_{M}^{4} .
\end{aligned}
$$

In equilibrium, the Kraus-Litzenberger CAPM given that $\bar{R}_{M} \sim N\left(\mu, \sigma^{2}\right)$ is

$$
E\left(\tilde{R}_{i}\right)-R_{f}=b_{1} \beta_{i}+b_{3} m_{i M M}
$$

where $\boldsymbol{b}_{\mathbf{3}}$ is negative under non-increasing absolute risk aversion. Since equation (A.5) holds for all $\boldsymbol{i}$ risky assets, it must also hold for the market portfolio $\mathbf{M}$. Setting $\boldsymbol{i}=\boldsymbol{M}$ results in

$$
E\left(\tilde{R}_{M}-R_{F}\right)=b_{1}
$$

Substitution of equation (A.6) into equation (A.5) yields

$$
E\left(\tilde{R}_{i}\right)-R_{F}=\beta_{i} E\left(\tilde{R}_{M}-R_{F}\right)+b_{3} m_{i M M}
$$

Taking the expected value of both sides of equation (A.1), equating this result with equation (A.7) and then rearranging terms results in

$$
c_{0 i}=\left(\beta_{i}-c_{1} J E\left(\tilde{R}_{M}-R_{F}\right)+b_{3} m_{i M M}-c_{2 i} \sigma_{M}^{2}\right.
$$

or equivalently using equation (A.3') and equation (A.4')

$$
c_{0 \mathrm{i}}=c_{2 i} \sigma_{M}^{2}\left(2 b_{3} \sigma_{M}^{2}-1\right) \text {. }
$$

Equation (A.9) is the restriction which the Kraus-Litzenberger version of the CAPM implies on the characteristic line given in equation (A.1)

\footnotetext{
${ }^{13}$ From statistics,

if $x \sim N\left(\mu, \sigma^{2}\right)$ so $E\left[(x-\mu)^{4}\right]=3 \sigma^{4}$.

$$
\frac{E\left[(x-\mu)^{4}\right]}{\sigma^{4}}=3
$$
}




\section{Appendix D: Correction for Smoothing in Real Estate Returns and Its Relationship to an AR(p) Process}

To correct for smoothing in both the EAI and farm real estate return series subcomponents of the USMI market proxy, the correction process elaborated on in Firstenberg, Ross, and Zisler (1988) is used. ${ }^{14}$ This process assumes that the expected return in period $\boldsymbol{t}$ is a combination of the true mean return $\boldsymbol{M}$, with four-period lag returns to generate the following estimation:

$$
E\left[\bar{R}_{t}\right]=(1-A) M_{t}+a_{1} \tilde{R}_{t-1}+a_{2} \tilde{R}_{t-2}+a_{3} \tilde{R}_{t-3}+a_{4} \tilde{R}_{t-4}
$$

where $A=a_{1}+a_{2}+a_{3}+a_{4}$ and $\mathrm{M}$, is the true mean return. The linear regression based on equation (B.1) yields

$$
\bar{R}_{t}=b_{0}+b_{1} \tilde{R}_{t-1}+b_{2} \tilde{R}_{t-2}+b_{3} \tilde{R}_{t-3}+b_{4} \tilde{R}_{t-4}+\tilde{z}_{t}
$$

where $\boldsymbol{z}_{\boldsymbol{t}}$ is the residual term. Combining equations (1) and (2), the authors show that the true mean return and the true standard deviation of returns is $\boldsymbol{M}=\left(\boldsymbol{b}_{\mathbf{0}} \div(\mathbf{1}-\boldsymbol{A})\right)$ and $\boldsymbol{\sigma}=\left(\sigma_{z_{t}} \div(\mathbf{1}-\boldsymbol{A})\right]$ where $\boldsymbol{b}_{\boldsymbol{i}}=\boldsymbol{a}_{\boldsymbol{i}}$ for $\boldsymbol{i}=1,2,3,4$. The resulting return series adjusted for smoothing, which is not shown in their article, involves taking the residuals from equation (B.2), adding the constant term $\boldsymbol{b}_{\mathbf{0}}$ from this equation, and then dividing this sum by the volatility smoothing factor $(\mathbf{1}-\boldsymbol{A})$ as follows:

$$
\tilde{R}_{t}^{*}=\left[\frac{z_{t}+b_{0}}{(1-A)}\right]=\left[\frac{\tilde{z}_{t}+b_{0}}{\left(1-b_{1}-b_{2}-b_{3}-b_{4}\right)}\right]
$$

Since it is easy to verify that equation (B.2) represents an $A R(4)$ process (see, for example, Pindyck and Rubinfeld, 1976, p. 458), we will now show that it is incorrect to adjust only the dependent variable prior to the estimation process in lieu of using an $A R(4)$ process. Recall from econometrics that if we have a model of the form

$$
\begin{aligned}
& \bar{R}_{j, t}=\alpha+\beta \bar{R}_{M, t}+\bar{\varepsilon}_{j, t} \\
& \tilde{\varepsilon}_{j, t}=b_{1} \tilde{\varepsilon}_{j, t-1}+b_{2} \tilde{\varepsilon}_{j, t-2}+b_{3} \tilde{\varepsilon}_{j, t-3}+b_{4} \tilde{\varepsilon}_{j, t-4}+\tilde{v}_{j, t} \quad 0 \leq b_{j}<1 \quad j=1,2,3,4
\end{aligned}
$$

where equation (B.4) holds for all time periods, then it follows that

\footnotetext{
${ }^{14} \mathrm{An}$ alternative correction process that one could employ is elaborated on in Geltner (1989).
} 


$$
\tilde{R}_{j, t-i}=\alpha+\beta \tilde{R}_{M, t-i}+\tilde{\varepsilon}_{j, t-i}
$$

Multiplying equation (B.5) by $\boldsymbol{b}_{\boldsymbol{j}}$ and subtracting the result from equation (B.4) for each of the four lags $j=1,2,3,4$, we obtain

$$
\tilde{R}_{j, t}^{*}=\alpha(1-A)+\beta \tilde{R}_{M, t}^{*}+\tilde{y}_{j, t}
$$

where

$$
\begin{aligned}
& \tilde{R}_{j, t}^{*}=\tilde{R}_{j, t}-b_{1} \tilde{R}_{j, t-1}-b_{2} \tilde{R}_{j, t-2}-b_{3} \tilde{R}_{j, t-3}-b_{4} \tilde{R}_{j, t \sim 4} \\
& \tilde{R}_{M, t}^{*}=\tilde{R}_{M, t}-b_{1} \tilde{R}_{M, t-1}-b_{2} \tilde{R}_{M, t+2}-b_{3} \tilde{R}_{M, t-3}-b_{4} \tilde{R}_{M, t-4}
\end{aligned}
$$

Finally, if we multiply equation (B.6) through by $(\mathbf{1}-\boldsymbol{A})^{-\mathbf{1}}=\left(\mathbf{1}-\boldsymbol{b}_{\mathbf{1}}-\boldsymbol{b}_{2}-\boldsymbol{b}_{\mathbf{3}}-\right.$ $\left.\boldsymbol{b}_{4}\right)^{-\mathbf{1}}$, the resulting equation is

$$
\tilde{R}_{j, t}^{* *}=\alpha+\beta \tilde{R}_{M, t}^{* *}+\tilde{v}_{j, t}^{*}
$$

where

$$
\begin{aligned}
& \tilde{R}_{j, t}^{* *}=\left[\frac{\tilde{z}_{t}+b_{0}}{(1-A)}\right]=\left[\frac{\tilde{z}_{t}+b_{0}}{\left(1-b_{1}-b_{2}-\bar{b}_{3}-b_{4}\right)}\right] \text { in equation } \\
& \tilde{R}_{M, t}^{* *}=\left[\frac{\tilde{R}_{M, t}-b_{1} \tilde{R}_{M, t-1}-b_{2} \tilde{R}_{M, t-2}-b_{3} \tilde{R}_{M, t-3}-b_{4} \tilde{R}_{M, t-4}}{(1-\mathrm{A})}\right] \\
& \tilde{v}_{j, t}^{*}=\left[\frac{\tilde{\varepsilon}_{j, t}-b_{1} \tilde{\varepsilon}_{j, t-1}-b_{2} \tilde{\varepsilon}_{j, t-2}-b_{3} \tilde{\varepsilon}_{j, t-3}-b_{4} \tilde{\varepsilon}_{j, t-4}}{(1-A)}\right]
\end{aligned}
$$

The point is that we also need to adjust each independent variable for smoothing in the dependent variable prior to the estimation process: for example, use $\widetilde{\boldsymbol{R}}_{\boldsymbol{M} \boldsymbol{t}}^{* *}$ rather than $\widetilde{\boldsymbol{R}}_{\boldsymbol{M} \boldsymbol{t}}$ in our regression model.

\section{References}

Barone-Adesi, Giovanni. "Arbitrage Equilibrium with Skewed Asset Returns." Journal of Financial and Quantitative Analysis 20 (September 1985), 299-313.

Breeden, Douglas, Gibbons, Michael, and Litzenberger, Robert. "Empirical Tests of the Consumption-Oriented CAPM." Journal of Finance 44 (June 1989), 231-261. 
Firstenberg, Paul, Ross, Stephen and Zisler, Randall. "Real Estate: The Whole Story." Journal of Portfolio Management 14 (Spring 1988), 22-34.

Friend, Irwin and Westerfield, Randolph. "Co-Skewness and Capital Asset Pricing." Journal of Finance 35 (September 1980), 897-913.

Gallant, A. Ronald. "Seemingly Unrelated Nonlinear Regressions." Journal of Econometrics 3 (1975): 35-50.

Gallant, A. Ronald. Nonlinear Statistical Models. New York: John Wiley, 1987.

Gallant, A. Ronald and Holly, Alberto. "Statistical Inference $\mathrm{n}$ an Implicit, Nonlinear, Simultaneous Equation Model in the Context of Maximum Likelihood Estimation." Econometrica 48 (April 1980), 697-720.

Gallant, A. Ronald and Jorgensen, Dale W. "Statistical Inference for a System of Simultaneous, Nonlinear, Implicit Equations." Journal of Econometrics 11 (1979), 275-302.

Geltner, David. "Estimating Real Estate's Systematic Risk from Aggregate Level Appraisal-Based Returns." AREUEA Journal 17 (Winter 1989): 463-481.

Gibbons, Michael R. "Multivariate Tests of Financial Models." Journal of Financial Economics 10 (March 1982) 3-27.

Ibbotson, Roger G. and Siegel, Laurence B. "The World Market Wealth Portfolio." Journal of Portfolio Management 9 (Winter 1983), 5-17.

Ibbotson, Roger G. and Siegel, Laurence G. "Real Estate Returns: A Comparison with Other Investments." AREUEA Journal 12 (Fall 1984), 219-242.

Jobson, J.D. and Korkie, Bob. "Potential Performance and Tests of Portfolio Efficiency." Journal of Financial Economics 10 (December 1982), 433-466.

Kraus, Alan and Litzenberger, Robert H. "Skewness Preference and the Valuation of Risk Assets." Journal of Finance 31 (September 1976), 1085-1100.

Lim, Kian-Guan. "A New Test of the Three-Moment Capital Asset Pricing Model." Journal of Financial and Quantitative Anaysis 24 (June 1989), 205-216.

Liu, Crocker H., Hartzell, David, Grissom, Terry and Greig, Wylie. "Alternative Rationales for Superior Real Estate Investment Performance: An Empirical Reinterpretation of Prior Research." Working Paper, New York University, May 1990a. 
Liu, Crocker H., Hartzell, David, Grissom, Terry and Greig, Wylie. "The Composition of the Market Portfolio and Real Estate Investment Performance." AREUEA Journal 18 (Spring 1990b), 49-75.

McCue, Tom. "Characteristics of Institutional Real Estate Investment." Doctoral dissertation, University of North Carolina-Chapel Hill, 1984.

Musgrave, John C. "Fixed Capital Stock in the United States: Revised Estimates." Survey of Current Business 61 (1981), 57-68.

Pindyck, Robert and Rubinfeld, Daniel. Econometric Models and Economic Forecasts. New YorkMcGraw-Hill 1976.

Roll, Richard. "A Critique of the Asset Pricing Theory's Test." Journal of Financial Economics 4 (March 1977) 129-176.

Roll, Richard and Ross, Stephen. "An Empirical Investigation of Arbitrage Pricing Theory." Journal of Finance 35 (December 1980), 1073-1103.

Ross, Stephen. "Return, Risk and Arbitrage." In I. Friend and B. Bicksler, eds., Studies in Risk and Return. Cambridge, MA: Ballinger, 1975.

Sears, R.S. and Wei, K.C.J. "Asset Pricing, Higher Moments, and the Market Risk Premium: A Note." Journal of Finance 40 (September 1985), 1251-1253.

Sears, R.S. and Wei, K.C.J. "The Structure of Skewness Preferences in Asset Pricing Models with Higher Moments: An Empirical Test." The Financial Review 23 (February 1988), 25-38.

Shapiro, S.S. and Wilk, M.B. "An Analysis of Variance Test for Normality." Biometrika 52 (1965), 591-611.

Stambaugh, Robert F. "On the Exclusion of Assets from Tests of the Two Parameter Model: A Sensitivity Analysis." Journal of Financial Economics 10 (November 1982), 237-268. 